\title{
A Comparison of the Impact of Protective and Presenvative Video Surveillance on Urban Temitoriality: the Case of Switzerland
}

\author{
Francisc o Kauser1
}

\begin{abstract}
This paper focuses on a comparison between two forms of video-surveillance and their consequences for the territoriality of public space users: the preservative, which aims to preserve public order and to prevent 'antisocial' behaviour; and the protective, which protect specific risk-points like buildings or objects. The fundamental difference between preservative and protective surveillance is linked to the spatial logic of its functioning, that can be deduced both from the position of the cameras and the general orientation of its view. Following Lefebvre and Raffestin, it argues that these socio-spatial relationships of social players may be considered as an inherent part of public space. In consequence, their transformation directly affects the qualities of public space. These theoretical explored are illustrated with a cartographical study of the cameras within the city centre of Geneva and a study of public sensitivity and perception of video surveillance in the Swiss city of Olten.
\end{abstract}

\section{Introduction}

The expansion of video-surveillance is often considered to be part of a general explosion of information and communication technology. Even if cameras are not the only surveillance devices proliferating in our cities (Brin, 1998: 6) they are often seen to be the tip of the iceberg built by relatively new surveillance and security technologies. While video-surveillance may be praised "as paving the way to a better future" by companies specialising in security technology (Videotronic, 2003) and as improving security within public space on the one hand, it might on the other land raise important concerns about the protection of privacy and potential social exclusion.

Quite often, this controversial discussion about positive and negative consequences of videosurveillance also occurs within research projects that examine issues of video-surveillance. Thus, video-surveillance is often analysed in terms of statistically measured levels of fear of crime or of rates of criminality, an approach focussing mainly on matters concerning the security problems

\footnotetext{
${ }^{1}$ Institut de Géographie, Université de Fribourg, Switzerland. mailto:francisco.klauser@unifr.ch
} 
of city centres. (Honess and Charman, 1992; Brown, 1995; Fyfe and Bannister, 1996) Furthermore, there has been much work on the consequences of video-surveillance concerning a new relationship of power between the watcher and the watched that may fundamentally alter the nature of social interaction within public space. In addition to this vision of video-surveillance as an instrument of power in a foucauldian sense, the sociological response to the general issue of video-surveillance has been dominated by images of the Panopticon, \& David Lyon has pointed out. (Lyon, 1994; Mc Cahill, 1998; Gandy, 1998; Haggerty and Ericson, 2000) In consequence, the main interest of many studies has been directed at large-scale publicly or privately owned CCTV security systems, that I will call preservative-surveillance (lat. preservare $=$ maintain) because of its extensive and wide ranging objective to preserve public order and to prevent 'anti-social' behaviour. However the majority of surveillance cameras that are focused on public space are not really meant to preserve public order in a whole but to protect specific risk-points like particular buildings or objects. In opposition to preservativesurveillance, this second CCTV category will be called protective-surveillance (lat. protegere $=$ to cover before, from). As I will argue, the fundamental difference between preservative and protective surveillance is linked to the spatial logic of its functioning, that can be deduced both from the position of the cameras and the general orientation of its view.

Thus, this present article focuses mainly on a comparison between these two forms of videosurveillance, and on its consequences for the territoriality of public space users. As Claude Raffestin points out, the concept of territoriality must be understood as a complex of relationships linking a population, group or individual to their social and spatial environment (Raffestin, 1984: 140). Within the theoretical introduction of this article I shall argue that these socio-spatial relationships of social players may be considered as an inherent part of public space. In consequence, their transformation directly affects the qualities of public space. In the second part of the paper, a cartographical representation of the cameras within the city centre of Geneva will illustrate the general spatial distribution of video-surveillance cameras. On this basis, different spatial concepts of surveillance will be examined - related to protective and preservative surveillance - in order to give more depth to the analysis of the effects of videosurveillance concerning the territoriality of public space users. Thirdly, the public sensitivity and perception of these two categories will be compared on the basis of research results for the Swiss city called Olten. Situated on the national north-south/east-west railroad and motorway intersection, Olten currently encounters various social problems because of its centrality (e.g.: drug dealing and prostitution). Because of the specific circumstances of police video-surveillance of street prostitution, public opinion about video-surveillance is especially interesting to study within this urban context. The Olten case study also seems to clearly illustrate the "struggle for space" between different social players and interests.

On a methodological level this article combines two empirical studies of video-surveillance that focus on two different Swiss cities. On the one hand, the spatial distribution of video-surveillance will be illustrated by the study of the city centre of Geneva that was done in summer 2001. On the other hand, the analysis of public perception of different types of video-surveillance is based on a postal public opinion poll for the city of Olten (summer 2003). 


\section{The theoretical approach of this work}

The general theoretical approach of this work is focused mainly on the concept of territoriality in order to understand the changing relationship between social players and public space because of video-surveillance. In view of the examination of the socio-spatial effects produced by video-surveillance, the general conception of public space will be presented and related to the concept of territoriality in the following section.

Within this article, public space is not only conceived from the perspective of its material form but also of the social processes that produced it. Consequently, in order to understand the qualities of public spaces, different social and physical levels must be taken into account. These levels must be understood as interactive and fundamentally interrelated. It is therefore necessary to consider not only the material and architectural structure of public space but also its social use and significance.

Thus, public space can be considered as socially 'significant space' that consists of signifiers (symbol), and signified (meaning). According to Raffestin, public space may be seen as public territory that results from collective and/or individual processes of spatial appropriation by action and representation. This appropriated space - as the object of collective intentions - takes part in reciprocal relationships with society: on the one hand, space is produced by the society and its inherent interactions of power. Therefore, public space cannot be an objective and neutral entity, but a socially produced socio-spatial reality. On the other hand, space produces society. According to the French philosopher Henry Levèbvre, a decisive part is played by space in the continuous reproduction of society (1968).

As a first approximation, public pace may be defined as "open, publicly accessible places where people go for group or individual activities" (Carr et al., 1992: 50). The central element of this definition of public space is its openness to social activities and use. On this theoretical basis, public space is conceived as democratically shared space that is characterised by its individual and collective users. Nevertheless, the history of public space can also be written as the history of its social regulation and socially defined use. Historical and contemporary studies have shown that not every public space is open to everybody, but very often, specific groups take control of specific public space and its use (Davis, 1999).

Not only the general access but also general qualities of public space in terms of social use, sociability and social control depend directly on the presence of its social users. To think of public space without its users and their relationships would be a limitation of its complex qualities. The concept of social players is therefore necessary, not only to "create" space but to constitute elements of space (Löw, 2001: 155).

In this sense, the qualities of public space depend on the presence (or absence) of social players, but also, crucially, on the relationships and interactions between them. In order to understand public space as lived and perceived space, it is therefore necessary to analyse both the relationship between social players related by public space, and their relationship with their 
physical environment. This leads to the concept of territoriality that is defined by Raffestin as a "system of relationships of a population or an individual with the outside world, and their modification by means of mediators" (Raffestin, 1984).

Two fundamental dimensions can be considered within this definition in strictly relational terms. On the one hand, territoriality includes the relational spectrum of individual or collective social players to their physical and social environment. On the other hand, territoriality is fundamentally based on the concept of mediators. As Raffestin has argued, every relationship of social players presupposes a mediation, which involves concrete or abstract instruments (means) of varying nature. For example, knowledge, language and behaviour can be seen as mediators, in that they affect relationships crucially. While mediators make relationships possible, they also influence and limit them. In addition, "mediators can be seen as constituting the conditions for the exercise of power, and they therefore define quite precisely the limits to liberty or autonomy of those who use them in their relationships with the exteriority [outside world]" (Raffestin, 1984: 141).

In the following analytical part of this article, I will consider CCTV as a material and symbolic mediator that changes interpersonal social relationships between the watched and the watcher as well as their relationship to public space. Furthermore, CCTV will be examined as an instrument that allows symbolic and material appropriatio $n$ of space and changes the qualities of surveyed places.

\section{Case Study: Geneva}

In summer 2001, over 270 surveillance cameras were discovered by personal observation in public streets and squares in the city centre of Geneva. (Within this study, only open "outdoor" public space was taken into account. This means streets, squares, pavements etc.) On this basis, it has become possible to illustrate the spatial distribution of video-surveillance, the typical categories of its users and the various objectives related to video-surveillance. On the basis of these results, various categories of visible video-surveillance of public space can be established (Klauser, 2001). Since there is no room here to discuss all the various forms of CCTV in detail, I will concentrate on two major categories of video-surveillance.

\section{Where does video-surveillance occur?}

Concerning spatial distribution of surveillance cameras, an important correspondence with the functional character of space can be seen. Concentrations of video-surveillance are mainly situated in areas with large numbers of banks, luxury hotels and international institutions along the north side of the lake as well as south of the outflow of the lake. It is interesting to note the absence of video-surveillance in the old-town of Geneva, which can be explained by the absence of banks and international luxury commerce (shops selling jewellery, watches, art or fashion). This finding illustrates the absence of outdoor video-surveillance of small, independent luxury shops until now in Geneva. There are also few outdoor cameras to be found within the red light 
district bordering the railway station ${ }^{2}$, as well as in the residential area in the south-eastern part near to the lake.

As well as indicating the private control of public space, this general review of video-surveillance distribution also illustrates varying degrees of social appropriation of the surveillance technology between international and national shops and institutions, as well as between different commercial specialities.

\begin{tabular}{|l|c|c|}
\hline & Cameras & Proportion \\
\hline Financial institutions & 105 & $37.9 \%$ \\
\hline Public institutions & 59 & $21.3 \%$ \\
\hline Hotels, Restaurants, Nightc lubs & 45 & $16.2 \%$ \\
\hline Fashion shops & 11 & $4.0 \%$ \\
\hline Others & 57 & $20.6 \%$ \\
\hline Total & 277 & $100 \%$ \\
\hline
\end{tabular}

Table 1: Users of video-surveillance

Geneva 2001, N=277

\section{Motives for video-surveillance}

A possible distinction amongst video-surveillance users would concern their public or private nature. As with other empirical research and cartographical representations of video-surveillance cameras, most of the cameras that have been found in Geneva belong to private institutions. However, some public institutions have also been found to use surveillance cameras in order to control public space in Geneva. At the same time, the reasons for installation as well as the general form of surveillance seem to be similar across most public and private systems in Geneva. The cameras are not organised in order to have the best view of public space, but their position follows the need for specific protection of buildings, financial capital or objects. This category of video-surveillance forms a contrast to large-scale CCTV systems that aim to cover extended urban areas. Regarding the spatial consequences of video-surveillance, it therefore seems relevant to differentiate not only owners but also objectives of surveillance.

On the one hand, a purely protection-oriented objective can be identified (protective surveillance), while on the other hand a behavioural improvement target (preservative surveillance) is indicated. Both types of video-surveillance can be seen in both private and public use. The fundamental difference between protective and preservative surveillance concerns the spatial concept of its functioning, which can be deduced both from the installation point of the cameras and the general orientation of their view.

\section{Protec tive surveillance}

More than 90 percent of the cameras detected in Geneva are fixed on private buildings in order to watch specific parts of the adjoining public street or pavement. The analysis of the field of vision of these cameras illustrates their very limited utility.

\footnotetext{
2 In Zurich, many more cameras have been found in the red-light district by Müller and Boos (2003). 
Firstly, the general view of the camera is defined by its installation. As the cameras are fixed on private buildings, public space and its users are really watched from a private point of view situated on the edge of public space. This decentralised and often immobile view - there are very few cameras of this type that can be manipulated by security operators - affects the possible selection of visual information. Secondly, the position and angles of the camera determine the geographic scale of surveillance. In the case of protective surveillance, the camera's position is likely to be quite vertical, in order to concentrate on one specific spatial point of risk. On the basis of these observations, the general aim of protective surveillance is the safeguarding of private property (objects, buildings and financial capital) from dangers coming from the adjoining public space. Therefore, very often, protective surveillance focuses on spatial points with easy access to private space, like shop windows or entrance doors.

Most of the cameras owned by public institutions that have been found in Geneva city centre also belong to this surveillance-category (examples include consulates, police stations and power stations). Again, the cameras do not cover the street for its own sake, but for the purpose of the protection of specific spatial risk points. Therefore, in contrast to preservative surveillance, the reason for protective surveillance is not the control of public streets or squares as an end in itself but the protection of public or private property. This general surveillance objective also limits the social processes of selection, evaluation and recording of the transmitted visual information. As there are no possible movements of the camera (modification of the position or zoom) the relationship between the watcher and public space users is therefore reduced to a privately defined minimum.

This selective surveillance of certain 'spatial points' may also be enlarged to 'spatial lines'. In this case, the visual protection might cover not only a specific point of interest like an entrance door, but the whole outer wall of the building. In consequence, the camera's position is often more horizontal in order to enlarge the surveyed portion of the space. Again, the cameras are not meant to control behaviour and social norms in public space as a whole, but only in relation to the owner's individually defined needs. Therefore, the key feature of CCTV as a normative and preservative measure, to generally modify people's behaviour, is much more limited in preservative surveillance.

People are only watched if they enter the surveyed part of the space. Their behaviour is exclusively of interest during their stay within sight of the camera. Therefore, this type of surveillance is not really focused on people but on parts of public space that are bordering private property. "The prime function of surveillance in the contemporary era is border control. We do not care who is out there or what they are doing. We want to see only those who are entitled to enter" (Boyne, 2000). The aim is not to discipline individuals as in Bentham's Panopticon, but to discipline the border between private and public space. There is no need to change the soul of the watched, but to guarantee an economic benefit for specific parts of public space. As there is mainly an individual and private benefit from these cameras, the risk of neglecting or displacing crime to poorer urban areas is not taken into account by such private camera operators. 


\section{Preservative surveillance}

In contrast with protective surveillance, preservative surveillance aims to control and normalise public space on a large scale. While the former controls individually defined spatial points, the latter focuses on larger 'spatial surfaces'. The main difference between these two categories of surveillance concerns therefore its geographic scale and spatial concept. Preservative surveillance not only tries to protect specific spatial points of risk, but also to monitor risks that are deployed within extensive areas (November, Klauser, Ruegg, 2002). Examples include vandalism in city centres or other deviant social behaviour that does not only concern one specific spatial point. For this reason, preservative surveillance generally uses a large network of pan tilt and zoom cameras. Because preservative surveillance often aims to follow individuals within the watched space, the position of the cameras is organised in order to maximise the extent of the observed space. Therefore, preservative surveillance systems are also more flexible. On the one hand, the organisation of the whole system can often be improved in order to eliminate blind spots or other technical difficulties. (November, Ruegg, Klauser, 2003) On the other hand, the security staff are often able to manipulate the position and focus of the cameras.

Even if many preservative surveillance systems are used by public authorities, private videosurveillance in shopping malls often applies very similar forms and spatial concepts of control. In both contexts video-surveillance is intended to improve the quality of social relationships and to create safe and risk-free (public) space. In addition, as Reeve has pointed out (1998), there is some resemblance between present-day development of city centres and shopping malls. While on the one hand shopping malls are often replacing traditional open public space in terms of public sociability (Davis, 1999; Carr et al., 1992; Valentine, 1996; Rauterberg, 2001) town centres are becoming increasingly focused on leisure and private interests that are monitored by video-surveillance (Reeve, 1998: 83).

There have actually been many studies about preservative surveillance in publicly or privately owned space. In consequence, in the following section, I will focus on protective surveillance and its implications for publicly owned public space. Nevertheless, in the last part of the article, public perception of protective and preservative surveillance will be compared.

\section{Protec tive video-surveillance and its implic ations for public space}

Although, as I have argued, there are very few studies about the consequences of protective surveillance cameras, heir rapid social and spatial expansion makes the analysis of their implications for public space very important.

First, protective video-surveillance allows its owners to widen their capacity to control public space. The territory of influence' of particular private or public players is extended into public space. Although there are very few studies about security staff interventions related to privately owned surveillance cameras that are watching parts of public space, there seem to be various types of reactions. Often, the real time monitoring of the images, as well as the measures taken in 
the case of observed misbehaviour, depend directly on the work done by the security staff (Norris, Armstrong, 1997). Performances by the Australian artist Denis Beaubois in Sydney's public squares consisted simply of staying motionless in direct view of surveillance cameras with his eyes fixed on the camera. According to Beaubois, very often this performance sooner or later provoked some sort of response:

"Sometimes it was so swift that Beaubois was escorted off the public premises only minutes after his arrival, the explanation being that he was disturbing the peace, or lacked a permit, or some equally inconsequential - and symptomatic bureaucratic banality. On aher occasions, where his stoic performances were graciously (even if often uncomprehendingly) tolerated by the authorities, it was the passers-by who became engaged by his presence, stopping to stare and enquire what exactly was going on."

(Levin, 2001: 81)

Similar observations have been made by the New York Surveillance Camera Players that stage theatre performances in front of public or private cameras. Comments put on the Internet about the course of events during their performances also illustrate the rapid and often violent reaction to behaviour which is conceived as 'deviant' (New York Camera Players, 2003).

As these examples show, there are various possible ways in which private camera users can intervene within public space. In addition, current trends in technical development leading to the construction of automated systems capable of recognizing people or incidents may widen the possibilities of private control and surveillance of public space. In this sense, private usage of public space for the purpose of commercial exploitation can be reinforced by its visual control. As a result, private protection surveillance enables private players to control the exploitation of public space.

According to the map of Geneva, some parts of public space in urban areas are closely monitored by private surveillance systems. As mentioned before, there is a very clear relationship between spatial density of financial institutions in particular and the spatial distribution of private video-surveillance. While the map of video-surveillance in Geneva illustrates the functional qualities of different parts of urban space, this unequal coverage of surveillance cameras can also reinforce the hierarchical organisation and fragmentation of urban public space. As a result, private video-surveillance may allow the reduction of public disorder within city centres, combined with the commercially motivated attraction of beneficial objects and people:

"Within this discourse CCTV cameras can be understood as helping to create public spaces for "free", "responsible", consumer-oriented individuals who independently choose their autonomous role in the life of the city. Thus CCTV is constructed around the idea of "empowerment" and "freedom", particularly the "freedom and safety to shop."

(Coleman and Sim, 2000: 635) 
Although the implications connected with video-surveillance of marginal social groups are not yet fully understood, the increasing spatial predominance of private surveillance cameras raises questions about increasing tendencies of privatisation and commercialisation of city centres. From this point of view, it would be of interest to study the everyday spatial practices of marginal groups in city centres closely monitored by private systems.

\section{Video-surveillance as access control}

Access control constitutes a particular case of protective surveillance. With regard to the general spatial concept of protective surveillance (the protection of specific spatial points of risk) an additional dimension is related to access control: the control of flows (of people and objects) between publicly and privately owned space.

As already mentioned, there are many private cameras that are watching public space in front of shop entrances. While these shops are basically open to customers, they are not accessible to everybody. The privately owned commercialised indoor space is generally limited to 'economically interesting' people (Schubert, 2000: 39). In this context, video-surveillance plays the role of a symbolic and physical mediator that communicates (symbolically) and enables (physically) the control and limitation of access. The video-monitored border between publicly and privately owned parts of the territory creates a relational stability between accessible and non-accessible places.

The automatic face recognition system at Zurich 'Unique Airport' is probably one of the purest examples of access control related to video-surveillance. According to statements of security officers, the automatic scan of passengers' faces is intended to enable the identification of already known illegal immigrants (Elsener, 10.1.2003: 3). In this particular case, access restriction is clearly related to the cameras' capacity to recognize people whose facial characteristics have already been scanned and recorded. However, access control within urban space may not only depend on the recognition of known individuals, but more generally on their physical appearance. Furthermore, restrictions to access private space are often extended to the adjoining public space (Simon, 2001).

In addition, public places like streets or squares can only be understood in relation to other publicly accessible (but privately owned) places. Particular localities do not exist in an isolated manner but as part of a complex system and network of localities (Huet, 1992: 18). As a result, restricted possibilities of access to certain parts of the network of localities will not only affect the qualities of the privately owned places but also of the remaining open space. The regulation of flows between private (inside) and public (outside) space will therefore also change the latter's qualities. According to Mats Franzen,

there is a constant negotiation between the anonymous public of a place and the activities bordering it. Consequently, the urban order in a particular place is determined, at least partially, by the unintended, and cumulative, consequence of all border controls. From a power point of view this is interesting. All activities 
operating "from the inside" are organized from the beginning, pursuing their own interests, while no one has any direct responsibility for "the outside", the urban order, except the police.

(Franzén, 2001:206)

The most perceptible consequence of access control concerns the territoriality of groups or individuals that do not have permission to pass. The interdiction to enter (generally) accessible places not only limits their relational spectrum to other social players but also their relation to the city in terms of daily spatial practices. Furthermore, attitudes toward the city will be different for people that may not be welcome to cross the border between publicly owned and privately owned publicly accessible space.

\section{Socialacceptance of private video-surveillance of public space}

Although private protective surveillance may therefore influence the perception and use of city space, at least in Switzerland, there is no public political or legal discussion about the appropriateness of these protection measures.

In order to deepen the understanding of privately owned and used (protective) videosurveillance within public space, some specific research results from a postal public opinion poll for the city of Olten will be used ${ }^{3}$. This preliminary study will raise elements of response and indicate further lines of research in order to understand the social perception of videosurveillance. As the main purpose of this article is to examine protective video-surveillance in comparison with preservative surveillance, the Olten case is particularly interesting, because it includes several forms of public conservation and private protection CCTV systems. I will therefore discuss questions concerning the awareness and acceptance of both public and private video-surveillance systems. Besides this quantitative approach, qualitative research will certainly be necessary in order to deepen the general understanding of video-surveillance.

At the beginning of 2001, the installation of a CCTV system in Olten - a small city of about 17,000 inhabitants - caused a lot of national and international media interest. Although two pedestrian subways within the city as well as the railway station have been video-monitored by the police for several years, German and Swiss television teams suddenly appeared in this city, located in the centre of Switzerland at the hub of the north-south and east-west road and railway routes, in order to have a look at the new CCTV system. This general attention was mainly motivated by the character of the street called 'Industriestrasse' that was considered to be the biggest centre of street prostitution in Switzerland. At present three dome-cameras are located along the 1.2 kilometre long streetwalking area. The data is transferred by a public network of optical fibres laid underground. This arrangement was mainly to facilitate the possible expansion

\footnotetext{
3 In a three-part questionnaire people were asked what they did in public space, their general perception of video-surveillance and their specific opinion concerning the surveillance of street prostitution in Olten. On the basis of 5621 original addresses, 1500 people were chosen according to their age structure. Unfortunately the original data basis did not contain a gender parameter. As a result, the gender balance within the 478 responses (31.9\%) varies considerably (62\% men, 38\% women), while the age structure is relatively even. Numbers of responses per age-category (10 years) vary between 89 and $111(18.3 \%-22.8$ $\%)$.
} 
of the system. The equipment for viewing and recording the transmitted information is located in the municipal police headquarters. In spite of the real-time screening of the transmitted information, there is no active observation of the material. However, as the policemen on duty explained, the images are sometimes consulted before going out on patrol.

\section{Public awareness of video-surveillance}

Surveillance cameras are often considered to be strongly symbolic features. In order to increase the preventive effects of video-surveillance, the visibility of the cameras is often consciously reinforced by large signs and/or media campaigns. On this basis, video-surveillance is often seen as a symbolic mediator that may change the behaviour of possible delinquents. However, concerning the everyday use of public space, many studies suggest that there may be very little public awareness of surveillance cameras (Klocke, 2001). The Olten study partially confirms this general finding. Within the questionnaire, people were asked to indicate general areas where they were aware of surveillance cameras in Olten:

\begin{tabular}{|l|l|}
\hline \multicolumn{2}{|c|}{ Where do you know about CCTV? } \\
\hline Public squa re & $0 \%$ \\
\hline Schools & $0 \%$ \\
\hline Child ren's playg round & $0 \%$ \\
\hline Resta urant & $1 \%$ \\
\hline Carpark & $21 \%$ \\
\hline Shops & $21 \%$ \\
\hline Shopping ma lls & $34 \%$ \\
\hline Railway station & $42 \%$ \\
\hline Street & $45 \%$ \\
\hline Bank & $51 \%$ \\
\hline Pedestrian subway & $52 \%$ \\
\hline
\end{tabular}

Table 2: Public awareness of video-surveillance Olten 2003, $\mathrm{N}=487$

Secondly, people were asked to give, if possible, specific examples of places equipped with surveillance cameras within the general areas. From these two questions, two main conclusions can be drawn:

1. Awareness is much greater in relation to public (preservative) cameras than in relation to private (protective) surveillance. Although many people think that there are cameras installed in banks, almost no specific examples were given. The same applies to shops and shopping malls. Therefore, it appears that in regard to the inside of shops, banks etc. people often assume the presence of cameras, but they do not really know about them. Beside that, no specific example was given for outdoor private (protective) cameras 
although there are several examples in Olten. In contrast, people were very well informed about most of the publicly used preservative cameras.

2. However, public awareness is not the same for all places of public surveillance. Three publicly used video-surveillance systems were mentioned very frequently: the railway station (105 mentions $=21 \%$ of all returned questionnaires), the street prostitution (186 $=38 \%)$, and the pedestrian subway rear the railway station called 'Winkel' (125= 26\%). Another publicly monitored pedestrian subway within the city centre (called 'Citypassage') was almost forgotten $(3=0.6 \%)$.

First of all, the awareness of surveillance of street prostitution seems to be influenced by the great media interest. Secondly, in regard to the other places of public video-surveillance, unequal awareness seems to be influenced by the perception of social risk related to the place. Actually, people were also asked to freely indicate places where they do not feel secure in Olten. While the railway station (147 responses) and the 'Winkel' pedestrian subway ( 82 responses) are by far the most feared places, the 'City-passage' was mentioned only 8 times.

On this basis, a plausible hypothesis to explain public awareness of video-surveillance would concern the personal perception of insecurity and risk within different places. At the same time, the degree of personal concern may also be an explanation for the very poor knowledge of private protective surveillance. People think that banks, shopping malls and shops are very often monitored by CCTV, but they do not know exactly which ones are, because it does not mean anything to them personally.

\section{Public acceptance of video-surveillance}

The general finding that public video-surveillance has a high level of public support (for example Ditton, Short, 1998) can be confirmed by the Olten study. For example, more than $60 \%$ of all participants agree with the statement 'those who have nothing to hide should not be afraid of CCTV", while only $18 \%$ disagree. However, regarding the Olten study, different factors seem to influence public opinion concerning video-surveillance. Firstly, the acceptance of videosurveillance seems to be influenced by the type and nature of the monitored place. In general, people are more likely to accept CCTV within functional places like car parks and pedestrian subways than in residential areas and public squares. The social relationship with space, that is a fundamental part of the concept of territoriality, seems therefore decisive in order to understand public acceptance of video-surveillance. Monitoring is less acceptable in places that are seen as belonging to the personal sphere, such as residential neighbourhoods. Moreover in spaces, which are designed to encourage sociability and the display of personal relationships, such as public squares, monitoring is also less acceptable. Finally, it would appear that work is considered by the vast majority of respondents as parts of the personal, not the public sphere and thus an inappropriate space for video-surveillance. 


\begin{tabular}{|l|l|l|l|l|}
\hline \multicolumn{5}{|c|}{ Where does videosurveillance disturb you? } \\
\hline & Disturbing & Neutral & Not Disturbing & No answer \\
\hline Car parking & $1 \%$ & $4 \%$ & $86 \%$ & $8 \%$ \\
\hline Pedestrian subway & $3 \%$ & $6 \%$ & $84 \%$ & $8 \%$ \\
Railway station & $3 \%$ & $7 \%$ & $77 \%$ & $14 \%$ \\
\hline Bank & $5 \%$ & $11 \%$ & $76 \%$ & $8 \%$ \\
\hline Shopping mall & $6 \%$ & $17 \%$ & $69 \%$ & $8 \%$ \\
\hline Luxury business (Inside) & $10 \%$ & $11 \%$ & $64 \%$ & $15 \%$ \\
\hline Clothing shops (Inside) & $12 \%$ & $12 \%$ & $62 \%$ & $15 \%$ \\
\hline Public transport & $14 \%$ & $23 \%$ & $57 \%$ & $6 \%$ \\
\hline Children's playground & $16 \%$ & $18 \%$ & $57 \%$ & $9 \%$ \\
\hline Public square & $18 \%$ & $18 \%$ & $47 \%$ & $16 \%$ \\
\hline Residential Neighbourhood & $31 \%$ & $19 \%$ & $37 \%$ & $13 \%$ \\
\hline Place of Work & $66 \%$ & $15 \%$ & $15 \%$ & $5 \%$ \\
\hline
\end{tabular}

Table 3: Public acceptance of videosuneillance

Olten 2003, N=487

In addition to the acceptance of visual surveillance according to the type of space involved, public opinion also differs with regard to private or public surveillance of public space. In fact, while public support for police surveillance is generally high, private (protective) cameras are regarded much more critically by the public. $47.6 \%$ of the answers wanted private institutions to avoid video-surveillance of public space, while only $26.8 \%$ were in favour. In this sense public acceptance of video-surveillance also seems to be motivated by its direct personal benefit.

\begin{tabular}{|l|l|}
\hline \multicolumn{2}{|c|}{$\begin{array}{c}\text { Private video-surveillance focussing on public streets } \\
\text { and pavements should be avoided }\end{array}$} \\
\hline Absolutely correct & $20.8 \%$ \\
\hline Comect & $27.0 \%$ \\
\hline Neutral & $19.3 \%$ \\
\hline Not true & $19.1 \%$ \\
\hline Not true at all & $7.2 \%$ \\
\hline Do not know & $4.9 \%$ \\
\hline No Answer & $1.6 \%$ \\
\hline
\end{tabular}

Table 4: The critical view of private video-surveillance Olten $2003, \mathrm{~N}=487$ 


\section{Conclusion}

The general aim of this article has been to analyse two forms of video-surveillance concerning their socio-spatial consequences for the territoriality of public space users. For this purpose, the analysis of spatial distribution of surveillance cameras in Geneva has been used in order to point out the general trend of private protective surveillance of public space such as streets, pavements and squares. Although this type of video-surveillance does not focus on behaviour within public space as a whole but on the protection of particular spatial risk-points, it has been argued that it may reinforce private control and influence on urban space by regulating flows between publicly and privately owned space. Autonomous choices concerning spatial activities within public space may be limited.

Concerning the concept of territoriality, the empirical findings have opened the way to investigation of possible effects on the relationship between different types of public space users on the one hand, and social players and the physical environment on the other. At the same time, the results of the Olten public opinion poll have shown that existing socio-spatial relationships with public space may also influence the general acceptance of surveillance measures. Videosurveillance may therefore not only change the territoriality of public space users, but also depend on it. Furthermore, it has been argued that public awareness of video-surveillance depends on the spatial concept of surveillance on the one hand, and on the personal concern about the surveillance measures on the other.

Regarding the low rate of public awareness concerning especially private protective surveillance that has been found, raises the question about the increasing risk to be mistaken about daily surveillance of one's practices within public space. According to Rössler, personal autonomy is also threatened if people are genuinely mistaken about the possibility that other people have information about them (Rössler, 2001: 233). From the point of view of monitored individuals within public places, the "disturbance in the relation between self and surrounding territory" (Olalquiaga, 1992 in Soja, 1996: 198), that Edward Soja notes regarding geographical experience of postmodernity in general, linked with "the growing incapacity of our minds to cognitively map not just the city but also the great global multinational and decentered communicational network in which we find ourselves caught as individual subjects" (Jameson, 1992 in Soja, 1996: 199) may therefore also be seen in connection to CCTV. In this sense, the consequences of video-surveillance on urban territoriality do not only concern access restrictions or increased use of places that are perceived to be safer because of surveillance cameras, but, more generally, the more far reaching relation between society and city space as a whole. This also leads to the question in what way security measures like CCTV may indeed transform the very society they are only designed to protect. 


\section{References}

Boyne, R. (2000) 'Post-Panopticism'. Economy and Society. 29(2): 285-307.

Brown, B. (1995) CCTV in Town Centres: Three Case Studies. Police Research Group, Crime Detection and Prevention Series: Paper no 68, Home Office Police Department: London.

Brin, D. (1998) The Transparent Society. Massachusetts: Perseus Books.

Carr, S. (1992) Public space. Cambridge: University Press.

Coleman, R. and J. Sim (2000) 'You'll never walk alone: CCTV surveillance, order and neo-liberal rule in Liverpool city centre'. British Journal of Sociology, 51: 623-639

Davis, M. (1994) City of Quartz, Ausgrabungen der Zukunft in Los Angeles. Berlin: Schwarze Risse.

Ditton, J. and E. Short (1998) 'Evaluating Scotland's first town centre CCTV scheme'. In Norris, C, Morran, J. and G. Armstrong (1998) Surveillance, CCTV and Social Control. Ashgate: Aldershot.

Elsener, R. (2003) 'Eine Kontrolle, die unter die Haut geht’. Neue Luzerner Zeitung, 10.1.2003: 3

Franzen, M. (2001) 'Urban order and the preventive restructuring of space: the operation of border controls in micro space'. The Sociological Review, 49(2): 202-217.

Gandy, O. H. (1998) 'The surveillance society: Information Technology and Bureaucratic social control'. Journal of Communication, 39(3): 61-76.

Haggerty, K. D. And R.V. Ericson (2000) The surveillant assemblage. British Journal of Sociology, 51: 605621

Honess, T. and E. Charman E. (1992) Closed Circuit Television in Public Places: Its Accebtability and Perceived Effectiveness, Home Office Police Research Group, Crime Prevention Unit Series, Paper No 35, London: Home Office.

Huet, B. (1992) 'Espaces publics, espaces résiduels'. In Charre A., (dir.) Art et espace publics, Givors : Maison du Rhône.

Klauser, F. (2001) La transformation de la territorialité urbaine en raison de la vidéosurveillance généralisée, Mémoire de licence, Département de Géographie, Université de Genève : Genève.

Klocke, G. (2001) 'Das Hintertürchen des Nichtwissens'. In Bürgerrechte \& Polizei, 69(2) At: http://www.cilip.de/ausgabe/69/video.htm

Levebvre, H. (1968) Le droit à la ville. Paris: Editions Anthropos.

Levin, T. Y. (2001) “"Where my tape, man?”: Denis Beaubois und die performative Politik des panoptischen Détournement'. In Südwestfunk Baden-Baden (ed.) CTRL [space], die wachsame gesellschaft, //internationaler/medien/kunst/preis 2001, Baden-Baden: Südwestfunk.

Löw, M. (2001) Raumsoziologie. Frankfurt am Main: Suhrkamp.

Lyon, D., 1994, The Electronic Eye: The Rise of the S urveillance Society. Cambridge: Polity Press.

Mc Cahill, M. (1998) 'Beyond Foucault : towards a contemporary theory of surveillance'. In Norris, C, Morran, J. and G. Armstrong (1998) Surveillance, CCTV and Social Control. Ashgate: Aldershot.

Müller, C. and D. Boos (2003) Kamerastandorte Kreis vier, Zürich, Karte und Liste. Unpublished. 
New York Surveillance Camera Players (2003). At: http://www.notbored.org/scp-performances.html.

Norris, C. and G. Armstrong (1997) 'Categories of control: the social construction of suspicion and intervention in CCTV systems'. A draft manuscript of The Rise of the Mass Surveillance Society, London: Berg.

November, V., Klauser, F. and J. Ruegg (2002) 'Risques sous surveillance: une analyse géographique de l'utilisation de la vidéosurveillance'. Ethique publique, 4(2): 153-164.

November V., Ruegg J. and F. Klauser (2003) Vidéosurveillance : mécanismes de régulation dans l'espace à usage public. Universités de Genève et de Fribourg, Rapport de recherche dans le cadre de l'Action COST A14 : Genève et Fribourg.

Raffestin, C. (1980) Pour une géographie du pouvoir. Librairies techniques : Paris.

Raffestin, C. (1984) 'Territoriality, A Reflection of the Discrepancies Between the Organization of Space and Individual Liberty'. International Political Science Review, 5( 2): 139-146

Rauterberg, H. (2001) 'Privat statt publik? Vom Wandel des öffentlichen Raumes'. Merkur, 4: 351-355

Reeve, A. (1998) 'The panopticisation of shopping: CCTV and leisure consumption'. In Norris, C, Morran, J. and G. Armstrong (1998) Surveillance, CCTV and Social Control. Ashgate: Aldershot.

Rössler, B. (2001) Der Wert des Privaten. Frankfurt : Suhrkamp.

Schubert, H. (2000) Städtischer Raum und Verhalten, Zu einer integrierten Theorie des öffentlichen Raumes, Opladen: Leske + Budrich.

Simon, T. (2001) Wem gehört der öffentliche Raum, Zum Umgang mit Armen und Randgruppen in Deutschlands Städten. Opladen: Leske + Budrich.

Soja, E.W. (1996) Thirdspace, Journeys to Los Angeles and Other Real-and-Imagined Places. Oxford: Blackwell Publishers Ltd.

Tyfe, N. R. and J. Bannister (1996) 'City Watching: Closed Circuit Television in Public Spaces'. Area, 28: 3746.

Valentine, G. (1996) '(Re)negotiating the "heterosexual street”: lesbian production of space'. In Nancy D. (ed.) (1996) BodySpace: Destabilizing Geographies of Gender and Sexuality. London: Routledge.

Videotronic AG (2003). At : http://www.videotronic.ch. 